\title{
Performance Analysis of Image Processing Algorithms using Matlab for Biomedical Applications
}

\author{
Garima Sharma \\ Research Scholar, Department of Electronics and Communication Engineering, Bhagat Phool Singh Mahila \\ Vishwavidyalaya, Khanpur Kalan, Sonipat, Haryana, India
}

\begin{abstract}
Image processing is used in every sphere of life such as agriculture, remote sensing, wireless, medical etc. Biomedical imaging plays a vital role in the detection of diseases. Without image processing, it is not possible to detect diseases such as cancer, tumors etc. Medical equipment such as ultrasound, MRI, CT scan machine is totally dependent on image processing algorithms. Radiologists utilize these image processing algorithms to detect diseases and abnormalities. Matlab is a proprietary tool which is used by image architects in order to design these algorithms. Image processing algorithms designed using Matlab provides efficiency, accuracy, flexibility and timing constraints. The present paper addresses various image processing algorithms designed using Matlab. The performance of these algorithms is also analyzed visually as well as statistically in order to check the quality of images.
\end{abstract}

Index Terms: Matlab, PSNR, Mean, Median, Edge detection.

(C) 2017 Published by MECS Publisher. Selection and/or peer review under responsibility of the Research Association of Modern Education and Computer Science.

\section{Introduction}

Image is formed by the combination of pixels. Image processing algorithms deal with the manipulation of these pixels. Image processing plays a vital role in the field of medical in order to detect artifacts and diseases. Image processing algorithms for biomedical equipment such as Ultrasound, MRI, CT scan machines are designed by image architects [40]. The radiologists utilize these algorithms to detect various diseases such as cancers, tumors etc [28].

Matlab is a proprietary tool which is highly used in various biomedical applications due to its flexibility, accuracy and timing constraints. It is used for software as well as the hardware implementation of images. It can interact with proprietary as well as open-source softwares. Matlab is also utilized for FPGA implementation of images [37]. Also, it has inbuilt support for some open source hardwares. For the healthcare industry, it is very

* Corresponding author. Tel.: 9896272540

E-mail address: firstgarima4@gmail.com 
important to extract accurate information in order to detect diseases [19]. Hence Matlab is a very effective tool for biomedical applications.

Image processing algorithms are based on mathematical modeling. There are various types of image processing algorithms which are utilized by biologists. Most commonly used image processing algorithms are image inversion, enhancement and segmentation. For image inversion, the image is complemented in order to extract information stored in dark pixels. Image enhancement algorithms are designed in order to improve brightness and contrast of image [15]. There are various filters used for image enhancement. Image segmentation algorithms are designed to detect the area of interest. In biomedical imaging, image segmentation is done in order to detect diseases such as tumors [39]. Edge detection is one of the important methods of segmentation [32]. There are various types of operators used for detecting edges. These include Sobel, Prewitt, Robert and canny operator [34]. These algorithms are generally used in diverse biomedical applications.

\section{Image processing Algorithms using Matlab}

Image processing algorithms using Matlab are designed by writing script files which consist of programming. In Simulink, there is no need to write codes. It is very important to check the quality of images after applying the algorithms. Hence visual and statistical analysis is performed in order to check the quality of processed images. In this, we proposed commonly used algorithms of image processing and analyzed the performance using Matlab/Simulink. We have designed image processing algorithms using Simulink and also analyzed statistical parameters to detect performance of designed algorithms. Computer vision library of Simulink is used for designing image processing algorithms. The proposed methodology of image processing algorithms using Matlab is depicted in figure 1.

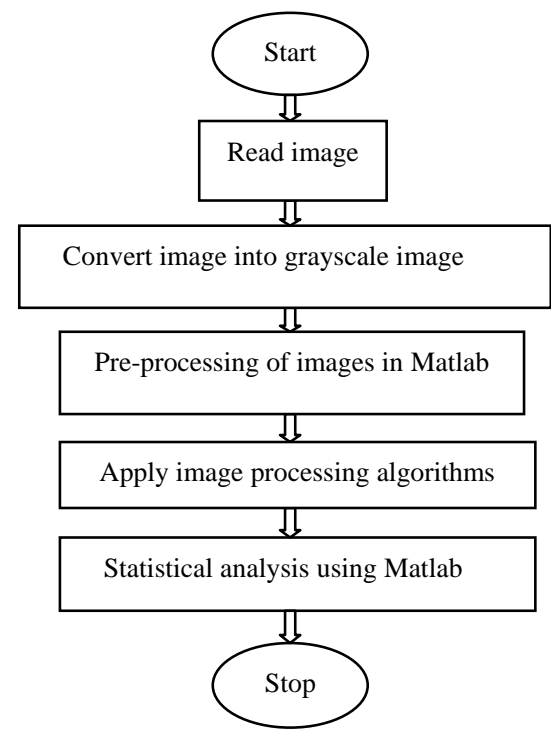

Fig.1. Design Flow of Image Processing Algorithms using Matlab

Images are first converted into grayscale images and then pre-processing is done in order to remove noises and then image processing algorithms are applied. The results of image processing algorithms using Matlab can be analyzed both qualitatively and quantitatively. Statistical analysis is done in order to check the performance of images quantitatively. 


\section{Performance analysis of images processing algorithms}

Three types of algorithms are generally required which are image inversion, image enhancement and image segmentation for disease detection. The performance of image processing algorithms can be obtained by analyzing the results visually as well as by calculating statistical parameters of images such as mean, median, standard deviation etc.

\subsection{Visual analysis using Matlab/Simulink}

In this, we have design image processing algorithms using computer vision library of Simulink. Image inversion is used in order to obtain the information hidden in dark pixels. Image inversion using Simulink is depicted in figure 2.

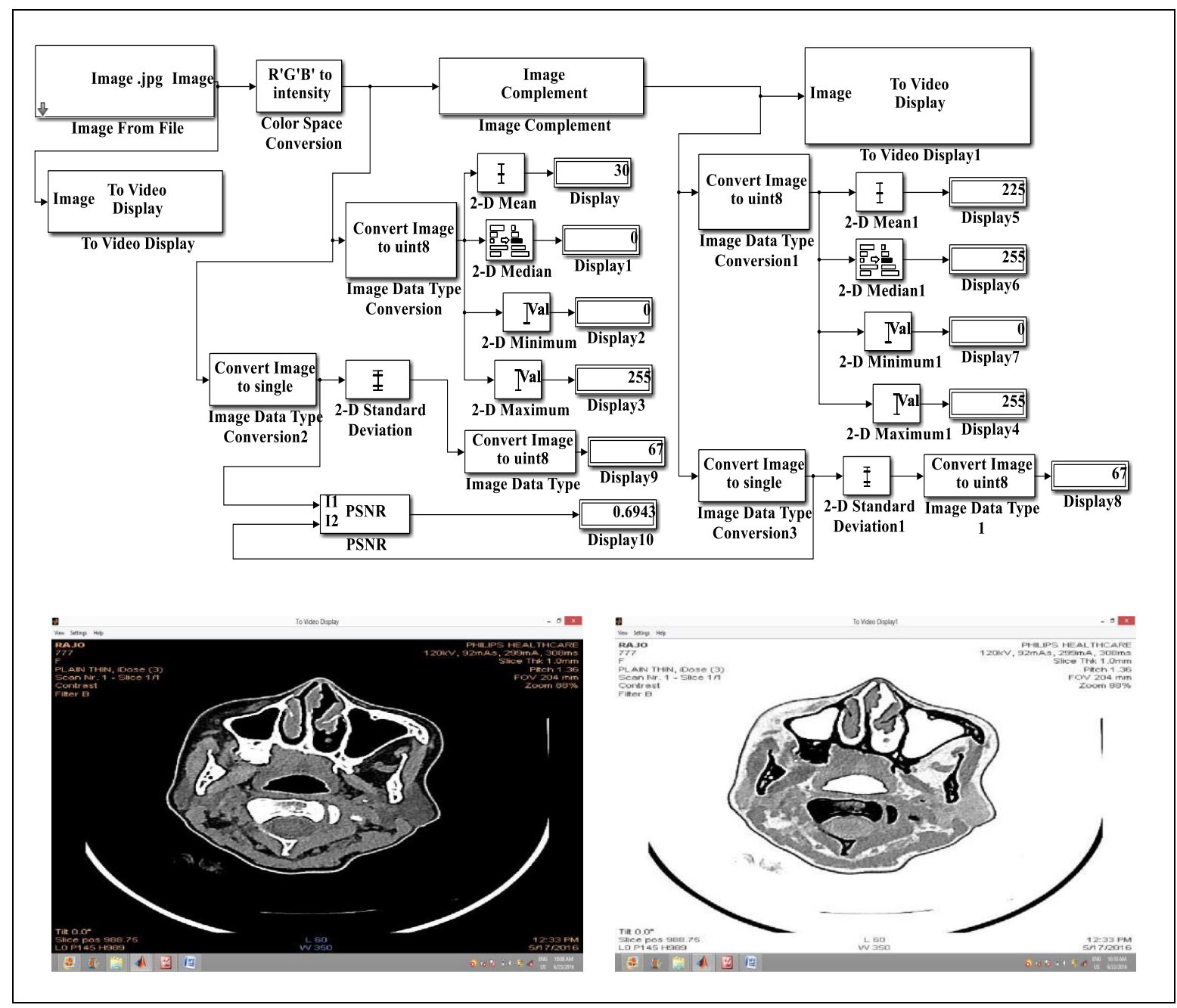

Fig.2. Image Inversion Model with Input and Output Image using Simulink 
Image enhancement algorithms are designed in order to improve the brightness of images so that biologists can get accurate information from the images [9]. There are different methods of image enhancement such as filtering, thresholding and contrast stretching etc. Various filters can be used to enhance the quality of images. Filters are used to remove the noise. The median filter is a nonlinear filter. It works on the principal of statistical ordering i.e. the response of this filter depends on the order of the values of neighborhood pixels. The Simulink model for image enhancement using median filtering is depicted in figure 3.

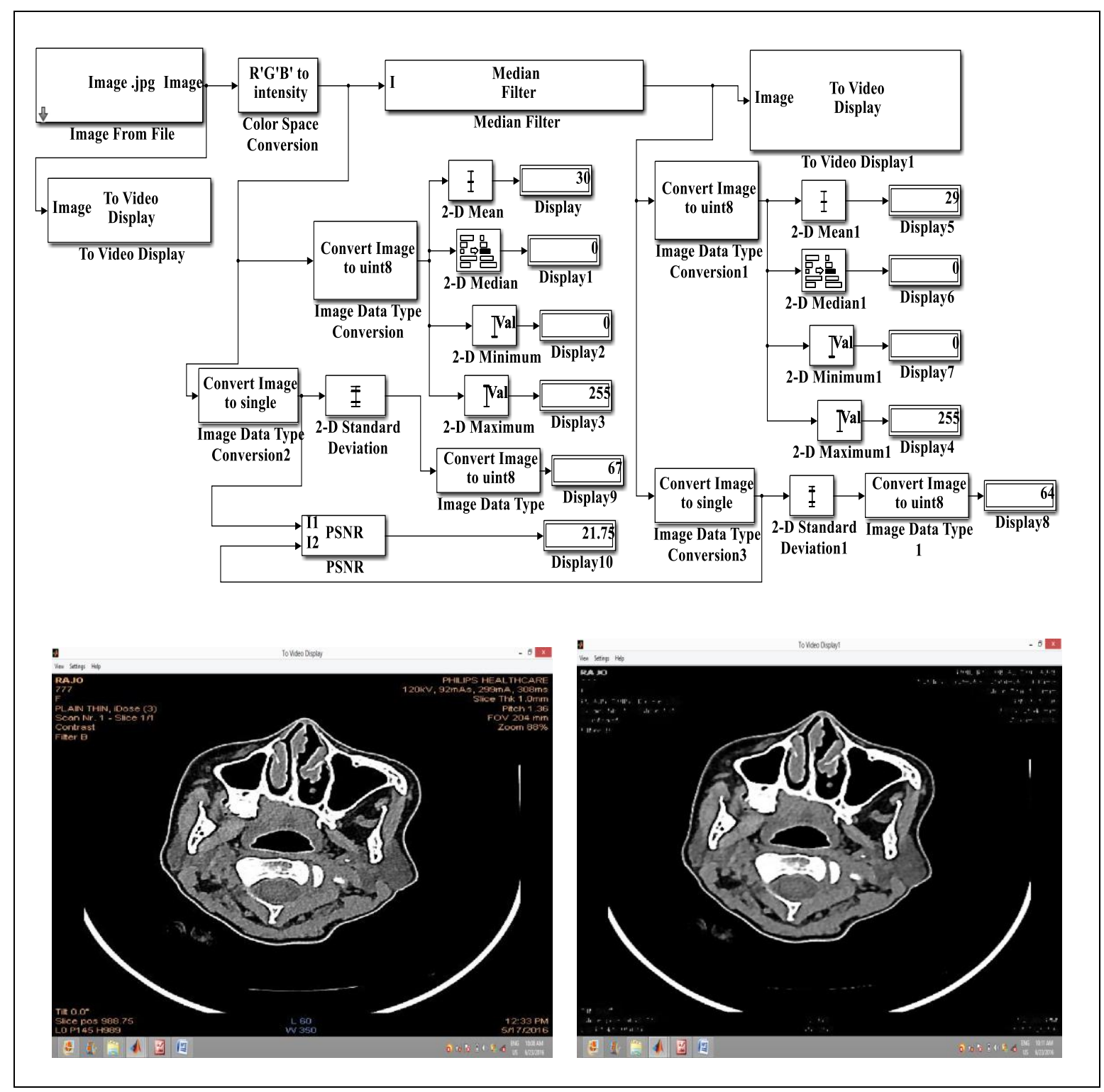

Fig.3. Image Enhancement Model using Median Filter with Input and Output Image using Simulink

Images can also be enhanced by adjusting its pixel values [31]. This can be achieved by adjusting the 
contrast of images. This method is used for enhancement of dark images. Image enhancement using contrast adjustment is depicted in figure 4 .

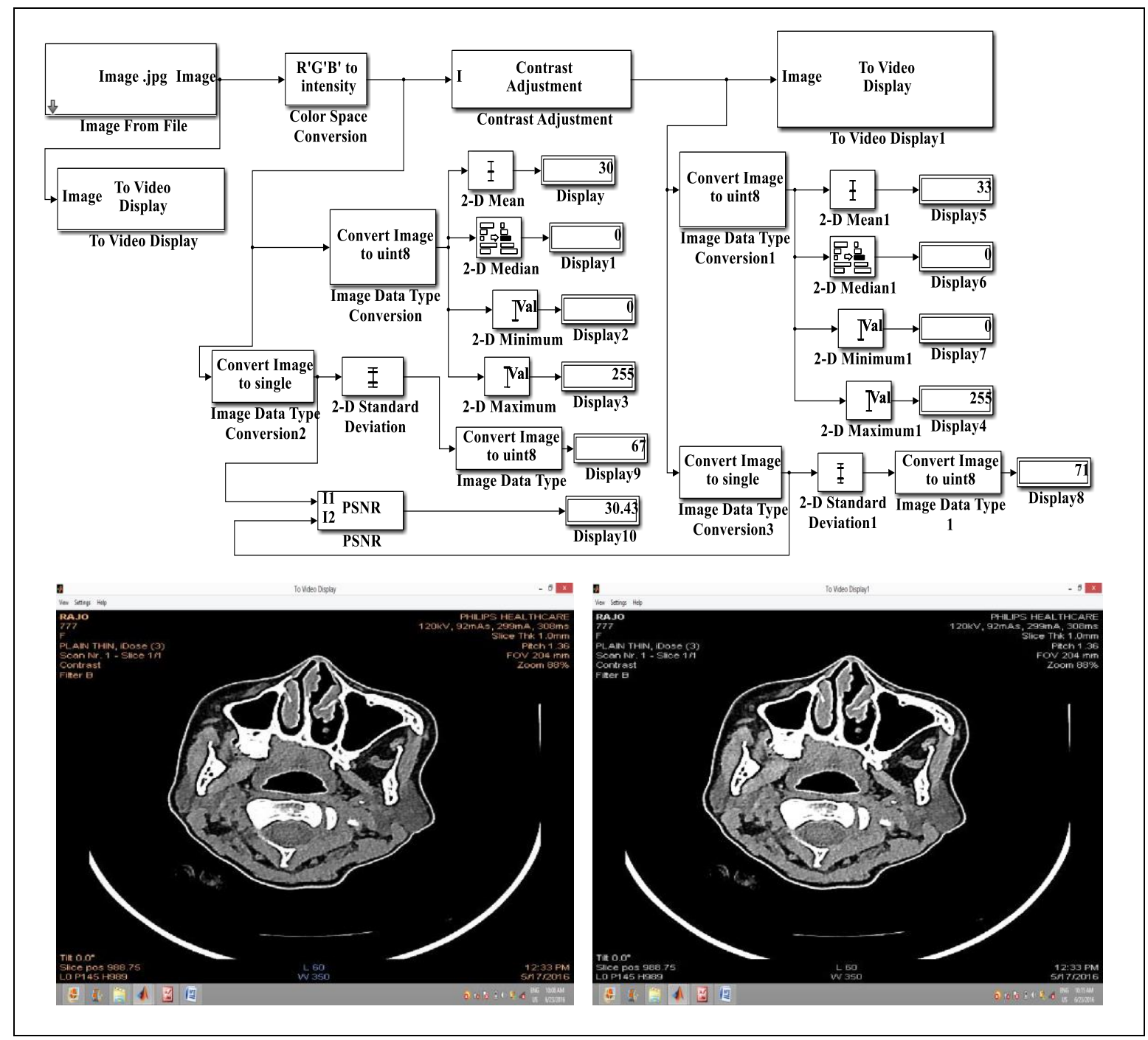

Fig.4. Image Enhancement Model using Contrast Adjustment with Input and Output Image using Simulink

Images enhancement algorithms are designed to improve the quality of image by sharpening the image [29]. The main objective of image enhancement is to change attributes of an image to make it more accurate for a specific application. One or more attributes of the image are modified in order to enhance the image. Image enhancement algorithms are broadly divided into two categories- spatial domain and frequency domain [2]. Thresholding is also used for image enhancement. It is also used for image segmentation. Thresholding image is a binary image which consists only either low or high value for corresponding pixel [36]. If the intensity is higher than a particular value called thresholding value then the image contain maximum value and if it is less than thresholding value then the value of processed image is zero. Simulink model for image enhancement using thresholding is depicted in figure 5. 


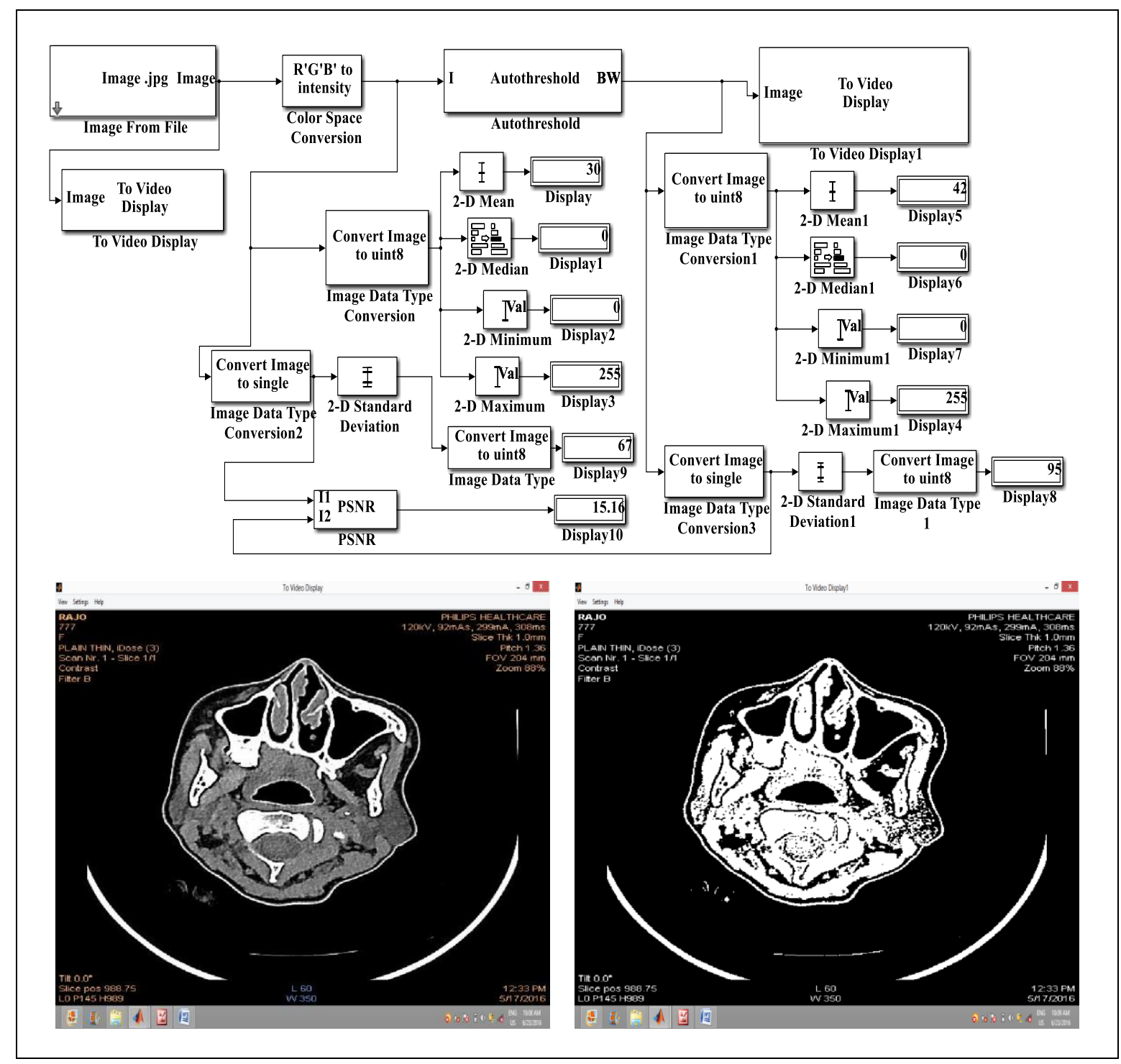

Fig.5. Image Thresholding Model with Input and Output Image using Simulink

Image segmentation [8] is the very important process used for detection of cancer, tuberculosis etc. There are various methods of the image which are used for different applications. Segmentation subdivides an image into its different parts. It is broadly divided into three categories - point, line and edge detection. There are various operators such as Sobel [17], Robert, Prewitt and canny etc which are used for designing edge detection algorithm. Edge detection using Sobel operator is depicted in figure 6. 


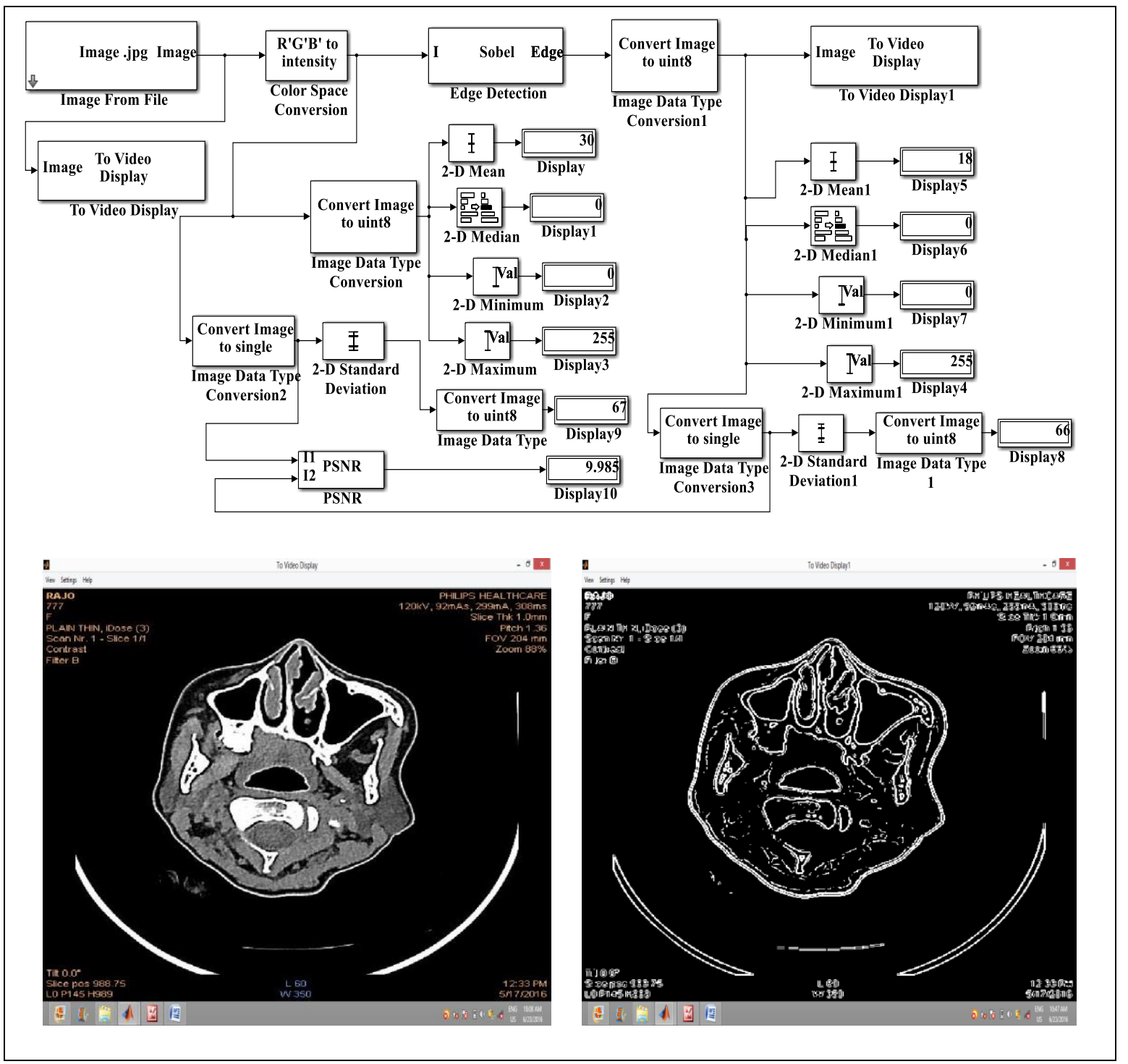

Fig.6. Sobel Edge Detection Model with Input and Output Image using Simulink

An edge is a defined as a boundary between two regions with different gray-level properties [16]. Edge detection algorithms play a crucial role to detect the exact location of desired areas. Different edge detection operators give different results visually as well as statistically [27]. It is very difficult to compare the performance of various operators. Image architects utilize various edge detection operators on the basis of the specific application. The Canny operator is also a very important operator which gives efficient results for edge detection [5]. Edge detection using canny operator is depicted in figure 7. 


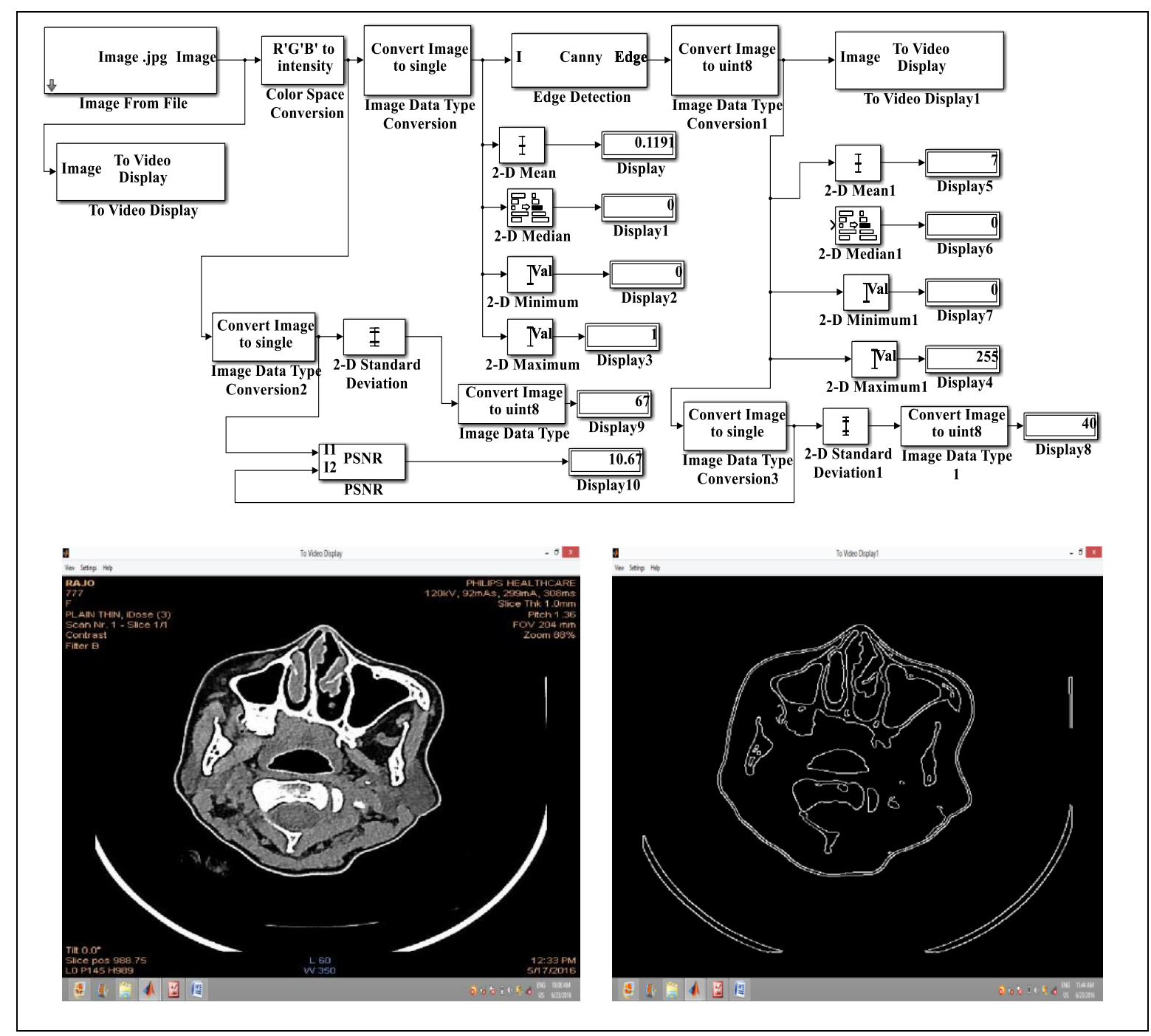

Fig.7. Canny Edge Detection Model with Input and Output Image using Simulink

Image processing algorithms are very important to analyze visually. But it is not only sufficient to analyze image visually because sometimes algorithms give similar result visually. Hence statistical analysis is done to detect the quality of applied algorithm.

\subsection{Statistical analysis using Matlab/Simulink}

Image processing algorithms such as image enhancement give same results visually. Hence it is not possible to detect the actual quality of images. Some mathematical parameters are calculated in order to check that which parameters provide better results [4]. Various statistical parameters are calculated using Simulink which can be utilized for calculating quality of proposed algorithms as depicted in table 1 . 
Table 1.Statistical analysis using Simulink

\begin{tabular}{|c|c|c|c|c|c|c|}
\hline $\begin{array}{l}\text { Sr } \\
\text { No. }\end{array}$ & Image Processing Algorithm & Mean & $\begin{array}{l}\text { Standard } \\
\text { Deviation }\end{array}$ & Minimum & Maximum & $\begin{array}{l}\text { PSNR wrt input } \\
\text { image }\end{array}$ \\
\hline 1 & Input Image & 30 & 67 & 0 & 255 & - \\
\hline 2 & Image Inversion & 225 & 67 & 0 & 255 & 0.6937 \\
\hline 3 & $\begin{array}{l}\text { Image enhancement using median } \\
\text { filter }\end{array}$ & 29 & 64 & & 255 & 21.75 \\
\hline 4 & $\begin{array}{c}\text { Image enhancement using contrast } \\
\text { adjustment }\end{array}$ & 33 & 71 & 0 & 255 & 30.43 \\
\hline 5 & Image autothresholding & 42 & 95 & 0 & 255 & 15.16 \\
\hline 6 & Sobel edge detection & 18 & 66 & 0 & 255 & 9.985 \\
\hline 7 & Canny edge detection & 7 & 40 & 0 & 255 & 10.67 \\
\hline
\end{tabular}

Statistical parameters are used to detect the quality of applied image processing algorithms. These parameters determine that which algorithm provide better results as compare to other. Although results obtained from different algorithms sometimes appears to be same visually but they are actually different. So these parameters calculate the results statistically [38]. Mean calculates the average intensity values whereas standard deviation calculates the variation in the intensity values of pixels. The minimum value for all the algorithms is 0 which indicate the smallest element in a row or column and maximum value for all the algorithms are 255 which indicate the value of the maximum element in a row or column. PSNR is peak signal to noise ratio which indicates the quality of images. PSNR of image enhancement algorithm using contrast adjustment is 30.43 and for median filter, PSNR is 21.75. It indicates that image obtained using contrast adjustment gives improved image as compared to median filter. Similarly, PSNR of canny edge detection is 10.67 where as 9.985 for Sobel edge detection. It indicates image obtained from canny edge detection gives better results as compared to Sobel edge detection. Hence all these parameters play very crucial role in estimating the quality of images. These parameters are very important for image architects in order to select the best algorithm. Image architects utilize the most accurate algorithm for designing equipment.

\section{Conclusion}

Biomedical instruments play a pivotal role in the detection of various diseases. These instruments use image processing algorithms which are designed by image architects. Biologists utilize these algorithms to detect artifacts and abnormalities. Matlab is a proprietary tool which provides accuracy and flexibility and timing constraints for. Image architects use Matlab for designing image processing algorithms. In this paper, we have designed various image processing algorithms using Matlab/ Simulink such as image inversion, enhancement and segmentation. We have analyzed the performance of these algorithms visually as well as statistically. Contrast adjustment gives better quality image due to its high PSNR as compared to other image enhancement algorithms. Similarly, the canny operator gives better quality as compared to the sobel operator for edge detection. The statistical parameters are very important to determine the quality of used algorithm. Hence Matlab is very flexible, efficient and accurate tool for designing image processing algorithms for biomedical applications.

\section{Acknowledgement}

Author would like to thank BPS Government Medical College for Women, Khanpur Kalan, Sonipat, Haryana, India for important and timely help in research. The work I present in this paper is completely supported by BPSMV, Khanpur Kalan, Sonipat, Haryana, India. 


\section{References}

[1] Parth V. Parikh, Bhinjan A. Dalwadi, Ghanshyam D. Zambare, "Sobel edge detection using FPGAArtix ${ }^{\circledR-7 ”, ~ I n t e r n a t i o n a l ~ J o u r n a l ~ o f ~ S c i e n t i f i c ~ \& ~ T e c h n o l o g y ~ R e s e a r c h, ~ V o l u m e ~ 5, ~ I s s u e ~ 6, ~ P P . ~ 250-253, ~}$ June 2016.

[2] Ramandeep Kaur, Kamaljit Kaur,"Study of Image Enhancement Techniques in Image Processing: A Review", International Journal of Engineering and Manufacturing (IJEM), Volume 6, Issue 6, PP. 38-50, 4 June 2016.

[3] S. R. Dixit, Dr. A. Y. Deshmukh, "Realization of canny edge detection algorithm using FPGA", International Journal of Engineering Sciences \& Research Technology (IJESRT), Volume 4, Issue 9, PP. 608618, September 2015.

[4] Shikha Maheshwari, Krishan Kumar, "Comparative analysis of lung cancer using different medical modality ", International Journal of Advanced Research in Computer and Communication Engineering, Volume 4, Issue 9, PP. 332-336, September 2015.

[5] Kaji Ahmed Asif Fuad, Shahriyar Masud Rizvi, "Hardware software co-simulation of Canny edge detection algorithm", International Journal of Computer Applications, Volume 122, Issue 19, PP. 7-12, July 2015.

[6] Dushyant Mankar, Prof. S. S. Mungona, "Models for MATLAB and XSG Simulink Based Edge Detection Operations", International Research Journal of Engineering and Technology (IRJET), Volume 2, Issue 3, PP. 1254-1257, June 2015.

[7] Nazia Abdul Majeed, Satheesh Rao, "FPGA Based Design Implementation for Detection of Exudates Using XSG", International Journal of Innovative Research in Computer and Communication Engineering (IJIRCCE), Volume 3, Issue 4, PP. 2818- 2825, April 2015.

[8] Harshada Shimpi, Nisha Gaikwad, Meghana Dhage, Prof. A. S. Pawar,“ Implementation of Edge Detection Algorithm Using FPGA", International Journal of Advanced Research in Electrical, Electronics and Instrumentation Engineering, Volume 4, Issue 4, PP. 2193-2197, April 2015.

[9] Kalyani A. Dakre, Prof. P. N. Pusdekar, "Image Enhancement using Hardware co-simulation for Biomedical Applications", International Journal on Recent and Innovation Trends in Computing and Communication (IJRITCC), Volume 3, Issue 2, PP. 869-877, February 2015.

[10] S. K. Areefabegam, T. Narendrakumar, "FPGA Based Design and Implementation of Image Edge Detection Using Xilinx System Generator", International Journal of New Trends in Electronics and Communication (IJNTEC), Volume 2, Issue. 8, PP. 18-21, November 2014.

[11] Ms. P.H. Pawar, Prof. R. P. Patil, "FPGA Implementation of Canny Edge Detection Algorithm", International Journal Of Engineering And Computer Science (IJECS), Volume 3, Issue 10, PP. 8704-8709, October 2014.

[12] K. Anil Kumar, M. Vijay Kumar, "Implementation of Image Processing Lab Using Xilinx System Generator", Advances in Image and Video Processing, Volume 2, Issue 5, PP. 27-35, October 2014.

[13] K. Naresh, M. Mahender, "Implementation of image edge detection using canny edge detection algorithm", International Journal of Scientific Engineering and Technology Research, Volume 3, Issue 29, PP. 5840-5844, October 2014.

[14] Amiket A. Ingle, Vrushali G. Raut, "Hardware software co-simulation of edge detection for image processing system using delay block in XSG ", International Journal of Research in Engineering and Technology (IJRET), Volume 3, Issue 8, PP. 549-553, May 2014.

[15] Mohammed Yousuf Khan, Masarath Nayeem Tayyaba, M. A. Raheem, Ayesha Siddiqua and Syed Sameena, "Image Enhancement and Hardware Implementation of Edge Detected Vascular Images using Simulink Model", International Journal of Advanced Research in Computer and Communication Engineering, Volume 3, Issue 4, PP. 6385-6388, April 2014. 
[16] Indrajeet Kumar, Jyoti Rawat and Dr. H.S. Bhadauria, “A Conventional Study of Edge Detection Technique in Digital Image Processing", International Journal of Computer Science and Mobile Computing, Volume 3, Issue 4, PP. 328-334, April 2014.

[17] Hong Nguyen T. K., Cecile. Belleudy, Tuan. V. Pham, "Performance and Evaluation Sobel Edge Detection on Various Methodologies", International Journal of Electronics and Electrical Engineering, Volume 2, Issue 1, PP. 15-20, March 2014.

[18] V. Kamatchi Sundari, M. Manikandan, P. Prakash, "FPGA Implementation of Sobel Edge Detector", International Journal of Advances in Science and Technology (IJAST), PP. 255-259, 15 February 2014.

[19] S W Harders, S. Balyasnikowa, B.M. Fischer, "Functional imaging in lung cancer", Clin Physiol Funct Imaging, Volume 34, Issue 5, pp. 340-355, 2014.

[20] Prof. Kamal A. El Dahshan, Prof. Mohammed I. Youssef, Dr. Emad H. Masameer, Mohammed A. Mustafa, "Hardware Segmentation on Digital Microscope Images for Acute Lymphoblastic Leukemia Diagnosis Using Xilinx System Generator", International Journal of Advanced Computer Science and Applications(IJACSA),Volume 5, Issue 9, PP. 33-37, 2014.

[21] M. Rathod, "Edge detection in VHDL", International Journal of Engineering Development and Research", Volume 2, Issue 1, PP. 1095-1099, 2014.

[22] Swapnil G. Kavitkar, Prashant L. Paikrao, "FPGA based image feature extraction using Xilinx System Generator", International Journal of Computer Science and Information Technologies, Volume 5, Issue 3, PP. 3743-3747, 2014.

[23] Praveen vanaparthy, Sahitya. G, Krishna Sree, Dr. C. D. Naidu, "FPGA implementation of image enhancement algorithms for biomedical image processing", International Journal of Advanced Research in Electrical, Electronics and Instrumentation Engineering, Volume 2, Issue 11, PP. 5747-5753, November 2013.

[24] Ravi.s, Abdul Rahim. B, Fahimuddin shaik, "FPGA Based Design and Implementation of Image Edge Detection Using Xilinx System Generator", International Journal of Engineering Trends and Technology (IJETT), Volume 4, Issue 10, PP. 4657-4660, Oct 2013.

[25] Priyanka Saini, Adesh Kumar, Neha Singh, "FPGA Implementation of 2D and 3D Image Enhancement Chip in HDL Environment", International Journal of Computer Applications, ISSN 0975-8887, Volume 62, Issue 21, PP. 24-31, January 2013.

[26] Sanjay Singh, Anil Kumar Saini, Ravi Saini, A. S. Mandal, Chandra Shekhar and Anil Vohra , "Area Optimized FPGA-Based Implementation of The Sobel Compass Edge Detector", ISRN Machine Vision, Article ID 820216, http://dx.doi.org/10.1155/2013/82 0216, 2013.

[27] H.P. Narkhede, "Review of image segmentation technique", International Journal of Science and Modern Engineering (IJISME), Volume 1, Issue 8, PP. 370-372, July 2013.

[28] Ying shin, Weihua Zhu, "Medical Image Processing - A Machine Vision Based Approach", International Journal of Signal Processing, Image Processing and Pattern Recognition, Volume 6, Issue 3, PP. 139-146, June 2013.

[29] S.S. Bedi, Rati Khandelwal, "Various Image Enhancement Techniques- A Critical Review", International Journal of Advanced Research in Computer and Communication Engineering (IJARCCE), Volume 2, Issue 3, PP. 1605-1609, March 2013.

[30] A. Radha, R. Priyakanth, "Performance Efficient FPGA Implementation of 2D Image Filtering Using Xilinx System Generator(XSG), International Journal of Electronics \& Communication Technology(IJECT), Volume 3, Issue 4, PP. 373-377, Oct-Dec 2012.

[31] Nirmala S. O, T. D. Dongale, R. K. Kamat, "Review of Image Enhancement Techniques: FPGA Implementation Perspective", International Journal of Electronics and Computer Technology (IJECCT), Volume 2, Issue 6, PP. 270-274, November 2012.

[32] Amandeep Kamboj and Anju Gupta, "Simulink Model Based Image Segmentation”, International Journal of Advanced Research in Computer Science and Software Engineering, Volume 2, Issue 6, PP. 146-149, June 2012. 
[33] Ravi Kumar A. V, Nataraj K.R, "Result Analysis of LabVIEW and MATLAB in Application of Image Edge Detection", International Journal of Computer Applications, Volume 48, Number 9, PP. 6-10, June 2012.

[34] Nikita Sharma, Mahendra Mishra, Manish Shrivastava "Colour image segmentation techniques and issues: An approach", International Journal of Scientific \& Technology Research(IJSTR), Volume 1, Issue 4, PP. 9-12, May 2012.

[35] A. C. Suthar, Mohammed Vayada, C. B. Patel, G. R. Kulkarni,“ Hardware Software co-simulation for Image Processing Applications", International Journal of Computer Science Issues (IJCSI), Volume 9, Issue 2, PP. 560-562, March 2012.

[36] Snehal O. Mundhada, Prof. V. K. Shandilya, "Image Enhancement and Its Various Techniques", International Journal of Advanced Research in Computer Science and Software Engineering (IJARCSSE), Volume 2, Issue 4, PP. 56-61, April 2012.

[37] Mrs. S. Allin Christe, Mr. M. Vignesh,Dr. A. Kandaswamy, "An efficient FPGA implementation of MRI, Image filtering \& Tumor characterization using Xilinx system generator", International Journal of VLSI design \& Communication Systems (VLSICS), Volume 2, Issue 4, PP. 95-109, December 2011.

[38] Adnan Al-Bashir, Bassam Al-Naami,“ A Fusion Technique Based on Image - Statistical Analysis for Detection of Throat Cancer Types”, Jordan Journal of Mechanical and Industrial Engineering (JJMIE), Volume 4, Issue 6, PP. 677-684, December 2010.

[39] "Medical Imaging Implementation Using FPGAs", Algorithm Development in Medical Imaging, Altera Corporation, PP. 1-10, July 2010.

[40] Habib Zaidi, "Medical image: Current status \& future perspectives", Division of Nuclear Medicine, Geneva University Hospital, DOI 10.1.1.15.5208, 2009.

\section{Authors' Profiles}

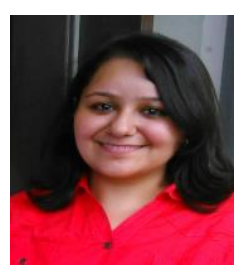

Garima Sharma is pursuing M.Tech (ECE) from Department of Electronics and Communication Engineering (ECE), BPSMV Khanpur kalan, Sonipat, Haryana, India. She completed her B.Tech degree in Electronics and Communication (ECE) from BPSMV Khanpur kalan, Sonipat, Haryana, India. Her area of interest includes Digital Image Processing and VLSI.

How to cite this paper: Garima Sharma,"Performance Analysis of Image Processing Algorithms using Matlab for Biomedical Applications", International Journal of Engineering and Manufacturing(IJEM), Vol.7, No.3, pp.8-19, 2017.DOI: 10.5815/ijem.2017.03.02 